\title{
Análise econômico-financeira de sistemas integrados para a produção de novilhas leiteiras
}

\author{
Oliveira Júnior, O.L. ${ }^{1,2}$; Carnevalli, R.A. ${ }^{2}$; Peres, A.A.C. ${ }^{3}$; Reis, J.C. ${ }^{2}$; Moraes, M.C.M.M. ${ }^{4}$ e Pedreira, B.C. ${ }^{2}$
}

'Programa de Pós-Graduação em Zootecnia. Universidade Federal de Mato Grosso. UFMT. Sinop. Mato Grosso. Brasil. ${ }^{2}$ Empresa Brasileira de Pesquisa Agropecuária. Embrapa Agrossilvipastoril. Sinop. Mato Grosso. Brasil.

${ }^{3}$ Departamento de Engenharia de Agronegócios. Universidade Federal Fluminense. UFF. Volta Redonda. Rio de Janeiro. Brasil. ${ }^{4}$ Hohenheim University. Stuttgart. Baden Württemberg. Germany.

\section{PALAVRAS CHAVE ADICIONAIS}

Análises de sensibilidade e risco.

Indicadores econômicos de rentabilidade.

Integraç̃o lavoura-pecuária-floresta.

\section{ADDITIONAL KEYWORDS}

Risk and sensitivity analyses.

Economic indicators of profitability.

Crop-livestock-forest integration.

\section{RESUMO}

Uma pecuária leiteira sustentável sob o ponto de vista ambiental e econômico é um grande desafio para a região Centro-Oeste do Brasil. Este estudo objetivou avaliar a viabilidade econômico-financeira de sistemas integrados para produção de novilhas leiteiras na região Norte do Estado de Mato Grosso. Foram avaliados dois sistemas para a produção de novilhas, assim identificados: sistema de integração lavoura-pecuária e sistema de integração lavoura-pecuária-floresta. Os sistemas foram monitorados entre 2010 e 2015, durante a fase de implantação e produção na Base Experimental de Produção de Leite em sistemas integrados da Embrapa Agrossilvipastoril em Sinop, Mato Grosso, Brasil. Projetou-se um horizonte para exploração de 14 anos, considerando uma área de 50 ha para cada Sistema Integrado. A partir do uso de planilhas eletrônicas foram projetados os fluxos de caixa para cada sistema para verificar a viabilidade econômico-financeira. Calculou-se o valor presente líquido, aplicando-se as taxas de descontos de 6, 8, 10 e 12\% ao ano. Os sistemas apresentaram valor presente líquido positivo quando submetidos à taxa de $10 \%$ ao ano. A taxa interna de retorno foi de $11,37 \%$ para o sistema integração lavoura-pecuária e a recuperação do capital investido foi de oito anos e oito meses. Para o sistema integração lavoura-pecuária-floresta, a taxa interna de retorno foi de 10,73\% e o tempo de recuperação do capital investido foi de oito anos e três meses. O preço de venda das novilhas leiteiras com prenhez confirmada foi o item de maior influência nos resultados dos sistemas. Os sistemas apresentaram baixo risco econômico-financeiro. Os sistemas integrados de produção de novilhas são financeiramente viáveis, tornando-se boas opções para investimento, recomendando-se a adoção em função do perfil individual do investidor, quer seja pela capacidade de assimilação e gestão da tecnologia, quer seja pela capacidade financeira disponível para investimento.

\section{Economic and financial analysis of integrated systems for the production of dairy heifers}

\section{SUMMARY}

Sustainable dairy farming from an environmental and economic point of view is a great challenge for the Midwest (Centro-Oeste) region of Brazil. This study aimed to evaluate the economic and financial feasibility of integrated systems for the production of dairy heifers in northern Mato Grosso. We evaluated two systems for the production of heifers, identified as follows: Integrated crop-livestock system and integrated crop-livestock-forest system. The systems were monitored from 2010 to 2015 , during the phase of implementation and production in the experimental basis of milk production in integrated Systems at Embrapa Agrossilvipastoril, in Sinop, Mato Grosso, Brazil. A horizon of 14 years of exploration was designed, considering an area of 50 ha for each integrated system. Cash flows spreadsheets to verify the economic and financial viability of each system were projected. We calculated the net present value, applying discount rates of $6,8,10$ and $12 \%$ per year. The systems had a positive net present value when subjected to a rate of $10 \%$ per year. The internal rate of return was $11.37 \%$ for the integrated crop-livestock system, and the recovery time of invested capital was 8 years and 8 months. For the Integrated crop-livestock-forest system, the internal rate of return was $10.73 \%$ and the invested capital recovery time was 8 years and 3 months. The selling price of dairy heifers with confirmed pregnancy was the item of greatest influence on the results of the systems. The systems had low economic and financial risk. Integrated production systems of heifers are financially viable, making them good options for investment. Their adoption must agree the individual investor profile, considering the capacity of assimilation and management of technology, and the financial capacity available of investment.
Cronología del arrículo.

Recibido/Received: 25.11.2015

Aceptado/Accepted: 15.03 .2016

On-line: 11.06 .2016

Correspondencia a los autores/Contact e-mail:

lelo@metal.eeimvr.uff.br 


\section{INTRODUÇÃO}

O Brasil é o país com maior potencial para aumento na produção leiteira no mundo. Segundo Ostrowski e Deblitz (2001), para que esse potencial seja alcançado, é necessário que a atividade leiteira se torne mais especializada, seja eficiente no setor produtivo e adote modelos de exploração adequados à realidade de cada região brasileira. No Estado de Mato Grosso, a atividade se apresenta com alto grau de amadorismo. Apesar da grande disponibilidade de terras, relevo plano, alta precipitação, temperatura elevada durante todo o ano e produção farta de grãos, a atividade leiteira no Estado é em sua maior parte extensiva e com baixo grau tecnológico. De modo geral, os produtores utilizam poucos insumos e em pequenas quantidades, o que explica os baixos valores do custo operacional efetivo, porém o alto valor do capital imobilizado na atividade explica o elevado custo operacional total e, por consequência, a baixa margem líquida (Famato, 2012).

Uma estratégia que tem se mostrado interessante para reduzir os custos de produção na atividade leiteira e otimizar os recursos dentro do sistema produtivo tem sido a segmentação da atividade e especialização do produtor aliado a sistemas mais completos de produção como os sistemas integrados. Desta forma, a produção de leite seria uma atividade isolada da produção de novilhas, minimizando os investimentos com esta categoria animal, porém sem perder a qualidade produtiva que deve ser o principal objetivo do criador (Hoffman e Funk, 1992).

A busca por maior eficiência produtiva e econômica conduz a atividade leiteira à utilização de sistemas mais complexos de produção, contudo, mais completos e sustentáveis, como sistemas integrados de produção. Estes sistemas integrados de produção reúnem atividades pecuária, agrícola e de silvicultura em uma única propriedade, utilizando-se dos benefícios mútuos, podendo gerar alimento de melhor qualidade para alimentação do rebanho durante o ano, além de propiciar renda complementar ao produtor com a venda dos excedentes agrícolas. Estudos têm evidenciado a importância e retorno de cultivos consorciados pelo mundo. Em regiões de semi-árido da Índia, o cultivo de milho, sorgo e milheto oportunizaram maior retorno de capital que o monocultivo (Ghosh, 2004). Em regiões frias do Canadá, Martin et al. (1990) encontraram taxas de uso da terra $10 \%$ maiores em milho consorciado e adubado. Na China, cultivos associados de árvores e arbustos para produção de chá foram $64 \%$ mais rentáveis do que seus cultivos isolados (Jianbo, 2006).

A necessidade de analisar economicamente qualquer atividade dentro da pecuária leiteira é importante, pois, permite ao produtor conhecer e utilizar os fatores de produção de forma consciente e sustentável. Na realização da análise econômico-financeira, preconiza-se determinar os principais indicadores econômicos de rentabilidade: valor presente líquido (VPL) e taxa interna de retorno (TIR). O VPL é uma fórmula matemáticafinanceira utilizada para calcular o valor presente de uma série de pagamentos futuros descontando uma taxa de custo de capital estipulada. Indica a viabilidade ou não de um projeto, sendo considerado um critério de avaliação de projetos mais rigoroso e isento de falhas técnicas (Contador, 1988). Quando o projeto apresentar VPL superior a zero significa que apresenta viabilidade econômica, pois será possível cobrir os seus custos de implantação e manutenção (Dantas, 1996). A TIR é utilizada para calcular a taxa de desconto que teria um determinado fluxo de caixa para igualar a zero seu VPL. Em outras palavras, seria a taxa de retorno do investimento em questão (Urtado et al., 2009). O payback é um dos indicadores utilizados na análise de retorno de projetos que indica o tempo necessário para o lucro acumulado gerado igualar ao investimento inicial, podendo ser demonstrado em unidade de tempo: dias, meses, anos (Urtado et al., 2009). A análise de sensibilidade permite observar de que maneira as variações ocorridas em uma das variáveis do projeto poderão influenciar sua viabilidade econômica. Com a análise de sensibilidade é possível determinar em que medida um erro ou modificação de uma das variáveis, incide nos resultados do projeto (Buarque, 1991). A análise de risco pode ser realizada utilizando o método de Monte Carlo para avaliar o risco envolvido nos sistemas integrados, comparando-os quanto à probabilidade de tornarem-se inviáveis, diante das oscilações de preços ocorridas no mercado (Peres, 2006). Este método permite superar as limitações das técnicas anteriores incorporando todas as combinações possíveis entre as variáveis, levando em consideração tanto as probabilidades de ocorrência de cada valor quanto às associações entre as variáveis (Oda et al., 2007).

Essas ferramentas disponibilizadas pela engenharia econômica vêm sendo aplicadas em avaliações de diferentes sistemas de produção aplicados ao agronegócio, permitindo assim aos investidores o acesso aos resultados econômicos, obtidos com a exploração destes. Para que a tomada de decisão seja mais coerente, é preciso conhecer sobre a viabilidade ou não de uma proposta de investimento, o retorno financeiro que será obtido, os itens que mais impactam e o risco que a atividade está submetida, frente às condições de mercado. As avaliações podem ser realizadas em sistemas exclusivos de produção agrícola, pecuária ou em silvicultura como na forma integrada de exploração. Diversos estudos têm sido conduzidos na avaliação técnica e econômica de sistemas de produção aplicados ao agronegócio.

Peres et al. (2015) trabalharam com diferentes sistemas suplementação mineral aplicados a criação de novilhas leiteiras em pastagem de capim-Xaraés. Neste trabalho, os autores observaram que sistemas de produção em pastagens cultivadas foram viáveis financeiramente, a uma taxa mínima de atratividade de $14 \%$ ao ano e, que o uso da suplementação mineral fornecida de forma adequada, melhorou os índices zootécnicos do rebanho e aumentou o retorno financeiro do capital investido. $\mathrm{O}$ uso de mistura mineral comercial é indicado, em regiões onde não se dispõem de ingredientes para fazer a formulação na própria fazenda, mas o estudo mostrou que a mistura mineral seletiva apresentou melhor resultado financeiro, devido à redução no custo operacional efetivo deste insumo, quando adquirido comercialmente. Nestes sistemas de produção, os autores observaram que o preço de comercialização das novilhas leiteiras com prenhez confirmada de quatro meses foi o item de 
maior impacto econômico na atividade, que apresentou baixo risco econômico para investimento. Em outro estudo, realizado por Peres et al. (2004), os autores observaram que o preço de venda das novilhas leiteiras foi aquele que apresentou o maior impacto negativo nos resultados econômicos de sistemas de produção em pastagens cultivadas de capim-elefante, com diferentes formas de suplementação alimentar.

Assim, objetivou-se analisar a viabilidade econômico-financeira de diferentes sistemas integrados para produção de novilhas leiteiras.

\section{MATERIAL E MÉTODOS}

O trabalho consistiu na avaliação de dois sistemas integrados de produção de novilhas leiteiras implantados na Base Experimental de Produção de Leite em Sistemas Integrados da Embrapa Agrossilvipastoril. O campo experimental está localizado no Município de Sinop, Estado de Mato Grosso, Brasil. A região é caracterizada como amazônica, sendo as coordenadas geográficas do local do experimento, $11^{\circ} 51^{\prime} 39.93^{\prime \prime}$ de latitude sul e $55^{\circ}$ 36'16.11" de longitude oeste e altitude média de 384 metros. O clima da região é do tipo climático Am, tropical de monção, segundo classificação Köppen. O período de avaliação econômico-financeira compreendido foi de julho de 2010 a abril de 2015.

A área total da base experimental era de 50 hectares, sendo destinados 10 ha às instalações, cria e recria de novilhas, canavial e armazenamento de forragens e os outros 40 ha divididos em quatro quadrantes de 10 ha cada, destinados a produção agrícola, pecuária e de silvicultura em associação. Os indicadores de produção agrícola, pecuária e de silvicultura foram determinados nos sistemas de produção entre os anos de 2012 e 2014. Durante o período de avaliação, o rebanho foi constituído de 36 novilhas mestiças (gir $x$ holandês), com percentual de sangue variando entre $3 / 4$ e $7 / 8$, adquiridas em setembro de 2012 com peso corporal médio de $150 \mathrm{~kg}$.

Os indicadores de produção agrícola foram obtidos por meio do acompanhamento das lavouras de milho-grão e milho-silagem, na safra, e feijão caupi, na safrinha, cultivados durante o período experimental. Por ocasião da colheita da produção, as áreas eram devidamente amostradas e seus valores de produção computados para posterior análise econômica. A produção animal foi obtida por monitoramento mensal do ganho de peso por meio de pesagem das novilhas e contabilização semanal da carga animal nas áreas de pastagem. A produção florestal foi obtida pelo cálculo de incremento de madeira anual obtido pelo monitoramento semestral de altura e DAP das árvores.

O sistema em integração lavoura-pecuária (ILP) foi composto por cultivo de lavoura, alternado com pastagem a cada dois anos, sem a presença de árvores, sistema este otimizado em termos de produção de alimentos, entretanto, sem a influência da presença de árvores. A área destinada neste sistema foi de 2,45 ha em cada quadrante. Cultivou-se o milho com Brachiaria ruziziensis, em dois dos quatro quadrantes da área, no início do período das chuvas, sendo que um quadrante destinado à produção de silagem e outro à produção de grãos. Após a colheita do milho para a produção de silagem, a forrageira foi dessecada e, em seguida, fez-se a semeadura do feijão caupi. Com a colheita do feijão caupi, o quadrante ficou em pousio até o próximo plantio com algumas plantas de Brachiaria ruziziensis remanescentes. O outro quadrante foi plantado com milho para produção de grãos e consorciado com Brachiaria brizantha, cv. BRS Piatã. Após a colheita do milho, a forrageira estabelecida tornou-se a pastagem por dois anos, quando era então, reformada novamente, completando o ciclo (figura 1). A pastagem estabelecida foi manejada sob lotação rotacionada, sendo a altura do dossel, o parâmetro adotado para o manejo da pastagem, determinando o ponto de entrada e saída dos animais com base na interceptação luminosa de $95 \%$ pelas forrageiras (Carnevalli et al., 2006).

O sistema de integração lavoura pecuária floresta (ILPF) apresentou lavoura e pastagem exatamente igual ao anterior com a diferença que este continha mais um componente no sistema, as árvores. O componente florestal caracterizou-se pela disposição das árvores nas áreas laterais, composto por dois renques de linhas duplas de eucalipto distantes 52 metros um do outro, porém com 49 metros de largura útil. Área total deste sistema foi de 2,6 ha em cada quadrante, sendo 2,45 ha utilizados para lavoura/pecuária e 0,3 ha utilizados para o componente florestal. Assim, área total destinada aos sistemas era de 9,8 ha e 10,4 ha para ILP e ILPF, respectivamente. Considerou-se que cada sistema tinha o correspondente a 2,0 ha destinados a instalações, canavial e armazenamento de forragens.

A estrutura implantada para condução dos experimentos e a escala de produção foram ajustadas para um cenário de fazenda real para aumentar a confiabilidade dos dados. O horizonte de exploração foi ampliado para 14 anos, a partir da aquisição da área. A projeção para o investimento foi estabelecida para uma área de 50 ha
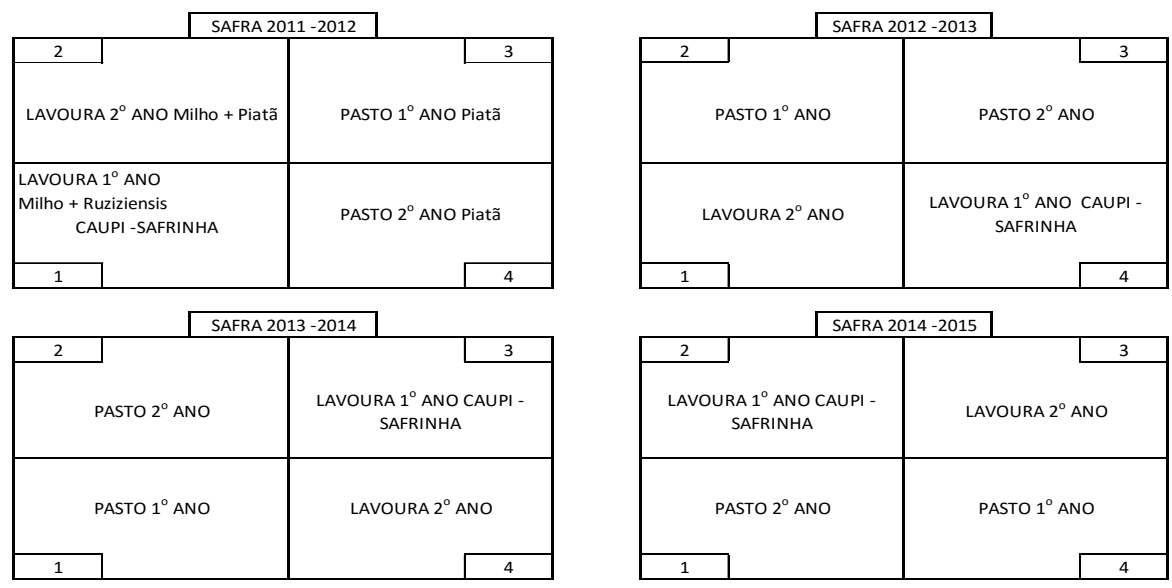

Figura 1. Croqui experimental e rotação das culturas durante o período experimental (Culture rotation during experimental period experimental sketch). 
para cada sistema, ajustando assim, a área da unidade experimental para a estrutura presente. A proposta de investimento considerou os 50 ha divididos em 6 ha de instalações, canavial e armazenamento de forragens e 44 ha divididos em quatro quadrantes de 11 ha cada que foram ocupados com lavoura e pecuária conforme o sistema. O manejo e os dados produtivos utilizados foram gerados na área experimental durante o período avaliado. A quantidade de animais foi ajustada para a área de 11 ha por quadrante de acordo com a capacidade de suporte da pastagem obtida em cada sistema. A definição do número de animais considerou a lotação das águas, já que houve suplementação na seca para manter a lotação. Os animais foram suplementados durante os meses de seca com silagem de milho e, posteriormente, cana-de-açúcar corrigida com ureia, em sistema de semiconfinamento, recebendo suplementação concentrada com fornecimento de ração proteinada (18\%).

A mão de obra utilizada foi composta por um funcionário fixo em cada sistema, para a execução das atividades diárias de manejo dos animais e condução da lavoura, e contratação de diarista esporadicamente para auxílio nas atividades de plantio, colheita e manutenção de cercas e benfeitorias em geral. Cada sistema foi assessorado tecnicamente por um veterinário por meio de visitas esporádicas e pelo administrador para controle das demais atividades. Todas as atividades relacionadas ao componente florestal do sistema ILPF foram executadas com mão de obra terceirizada.

A identificação de todos os insumos utilizados para implantação e exploração, bem como os valores pagos e as receitas obtidas, em reais foram determinados para cada sistema de produção avaliado. Esse levantamento foi realizado por meio da coleta de informações inerentes as práticas ocorridas nos sistemas e também em visitas periódicas, utilizando-se fichas de anotações a campo para registro, das informações, promovendo maior organização e padronização das informações coletadas. Procedeu-se a caracterização de cada sistema de produção após a coleta de todas as informações produtivas e econômicas. Procedeu-se à caracterização do sistema de produção e a tabulação das informações econômicas

Tabela I. Descrição das entradas (receitas) e saídas (despesas) envolvidas nos sistemas de produção integrada (Description of the inputs (income) and outflows (expenses) involved in integrated production systems).

\begin{tabular}{|c|c|}
\hline \multicolumn{2}{|l|}{ Receitas (Entradas) } \\
\hline Categoria & Descrição \\
\hline Pecuária & Novilha com prenhez confirmada (4 meses - 400 kg), novilha descarte e mortalidade. \\
\hline Agricultura & Milho grão, feijão caupi. \\
\hline Silvicultura & Madeira de eucalipto para lenha. \\
\hline Valor imobilizado & Terra, benfeitorias, equipamentos, máquinas, veículos, ferramentas e cercas. \\
\hline \multicolumn{2}{|l|}{ Despesas (Saídas) } \\
\hline Categoria & Descrição \\
\hline Valor investido & $\begin{array}{l}\text { Terra (área), benfeitorias (curral, galpão, escritório, banheiro, poço semi-artesiano, tronco de contenção,...), } \\
\text { equipamentos (caixa d'água, bebedouros, cochos, balança, eletrificador, voltímetro, botijão de sêmen, carrinho } \\
\text { de mão, roçadeira costal, pulverizador costal...), máquinas (desintegrador, picadeira, misturador de ração, } \\
\text { carreta,...), veículos (quadriciclo), ferramentas (pá, enxada, foice, facão, martelo, alicate, turquez, brincador, } \\
\text { pistola de vacinação,...) e cercas (convencional e elétrica). }\end{array}$ \\
\hline Pecuária & Bezerra desmamada para reposição (6 meses / 150 kg). \\
\hline Nutrição animal & Ração concentrada e sal mineral. \\
\hline Sanidade animal & $\begin{array}{l}\text { Vacina, carrapaticida, bernicida, antibiótico, antiinflamatório, antitóxico, repelente, pomada para cicatrizante, } \\
\text { exames de sanidade, brinco de identificação,... }\end{array}$ \\
\hline Reprodução animal & Materiais para inseminação artificial em geral, aplicador, pipeta plástica, luva, sêmen, nitrogênio líquido. \\
\hline Pastagem e silagem & Corretivos, fertilizantes (N, P, e K), inseticida microbiológico, inseticida sistêmico, herbicida, sementes,... \\
\hline Canavial & Corretivos, fertilizantes (N, P, e K), mudas de cana, cupinicida, herbicida,... \\
\hline Agricultura & $\begin{array}{l}\text { Semente (milho, feijão caupi, forrageiras), corretivos, fertilizantes (N, P, e K), herbicida, inseticida, inoculante } \\
\text { biológico, fungicida,... }\end{array}$ \\
\hline Floresta & $\begin{array}{l}\text { Mudas (eucalipto e castanheira), corretivos, fertilizantes (N, P, K e FTE BR-12), inseticida, formicida, herbicida } \\
\text { seletivo,... }\end{array}$ \\
\hline Serviços terceirizados & Contratação de máquinas e implementos agrícolas para atividades diversas. \\
\hline Mão de obra & $\begin{array}{l}\text { Contratada (funcionário de campo e administrador), temporária (inseminador, diagnóstico de palpação, cons- } \\
\text { trução de cercas, manutenção de benfeitorias, preparação e plantio de culturas, diarista,...) e prestador de } \\
\text { serviços (zootecnista, engenheiro agrônomo, médico veterinário, contador,...). }\end{array}$ \\
\hline Combustíveis & Energia elétrica, gasolina, lubrificante e graxa. \\
\hline Impostos e taxas & ITR, Funrural, encargos sociais e trabalhistas, outros custos (carretos, fretes,...). \\
\hline Outros itens & Material de escritório, reparo e manutenção (benfeitoria, máquina, equipamento, ferramenta,...). \\
\hline
\end{tabular}


em planilhas eletrônicas (MS-Excel ${ }^{\circledR}$ ) permitindo uma melhor dinâmica e visualização de cada sistema de produção e construção do fluxo de caixa. Em cada fluxo de caixa foram computadas as entradas (receitas) e saídas (despesas) envolvidas, possibilitando a obtenção do fluxo líquido, mensalmente. Admitidas como entradas, as receitas obtidas foram resultantes da venda de animais, do milho grão, do feijão caupi e da madeira de eucalipto destinada para lenha. Como despesas, incorridas em todo o processo produtivo foram consideradas a compra de insumos, manutenção de benfeitorias, máquinas e pastagens, as operações mecanizadas, o pagamento da mão de obra, os gastos com alimentação, medicamentos, taxas, impostos e outros itens considerados essenciais à manutenção dos sistemas de produção. Considerou-se ainda, o investimento realizado na compra de terra e construção de instalações e benfeitorias necessárias ao funcionamento dos sistemas de produção (tabela I).

Em adição ao fluxo de caixa, foi elaborada uma planilha de preços praticados na região que teve o mesmo horizonte daquele considerado para a implantação e exploração dos sistemas de produção. Estes preços foram corrigidos monetariamente para o mês de maio de 2015, utilizando o IGP-DI, índice geral de preços - disponibilidade interna (FGV, 2015) como indicador financeiro utilizado para realizar a deflação dos preços. Os preços considerados foram àqueles praticados nos sistemas de produção, bem como aqueles que ocorreram na região sendo obtidos por meio de nota fiscal de compra, consulta a lojas agropecuários, revendas agrícolas e profissionais que atuam no setor dos agronegócios. Posteriormente, determinou-se por meio da distribuição triangular os preços mínimo, médio e máximo, de acordo com a metodologia descrita por Atkinson et al. (2015).

Para realização da análise econômico-financeira foram determinados os principais indicadores econômicos de rentabilidade (Contador, 1988; Blank e Tarquin, 2008): valor presente líquido (VPL) e taxa interna de retorno (TIR) e realizadas as análises de sensibilidade (Buarque, 1991) e risco (Oda et al., 2007). Determinou-se também o payback descontado (Blank e Tarquin, 2008) em cada sistema de produção. Os cálculos foram realizados utilizando o fluxo de caixa mensal, que corresponde à diferença entre as receitas e despesas realizadas em cada sistema de produção. Para o cálculo do VPL, aplicaram-se diferentes taxas de desconto de 6, 8, 10 e $12 \%$ ao ano sobre o fluxo líquido mensal dos sistemas e adotou-se como taxa mínima de atratividade, a remuneração média obtida com os investimentos realizados na caderneta de poupança, durante os anos de 2010 a 2014, que oscilou entre 6,31\% e 7,50\% ao ano (Portal Brasil, 2015).

Para a realização da análise de sensibilidade, os itens que compõem o fluxo de caixa de cada sistema de produção foram estudados individualmente, sendo observado o impacto negativo que cada item causou sobre o fluxo de caixa, sempre na condição desfavorável ao investidor, ou seja, quando o empreendimento apresentou queda nas receitas ou aumento nas despesas. Essa técnica indica o quanto o VPL varia em resposta à mudança do valor de um determinado item do fluxo de caixa, mantendo os valores dos outros itens constantes. Adotou-se uma variação de dez pontos percentuais para baixo nos valores dos itens de receitas (entradas) e de dez pontos percentuais para cima nos valores dos itens de despesas (saídas) de acordo com a metodologia descrita por Weston e Brigham (2000). A partir daí, foi possível observar qual item apresentou maior efeito sobre o VPL, sendo considerados os quinze itens que causaram maior variação no VPL e classificados por ordem de importância.

Na realização da análise de risco, adotou-se o método de Monte Carlo proposto por Noronha (1987) que considerou a probabilidade de insucesso do sistema de produção sobre o risco que cada um apresentou diante das oscilações de preços ocorridas no mercado. Por não ser possível avaliar a influência de todos os itens simultaneamente, a melhor alternativa foi identificar os itens de maior impacto e, considerou os preços mínimo, médio e máximo dos itens para realizar a variação de preços considerada na análise de risco, pelo método de Monte Carlo. Foram gerados 50000 fluxos de caixa, simultaneamente que resultaram na probabilidade de insucesso de cada sistema de produção. Com o resultado obtido foi possível identificar o risco econômicofinanceiro de cada sistema de produção. Esta operação foi realizada um número significativo de vezes, o que significou a geração de 50000 possibilidades de ocorrência para o fluxo de caixa, com os preços variando entre o intervalo determinado, durante o período de avaliação, conforme metodologia descrita por Hertz (1964).

\section{RESULTADOS E DISCUSSÃO}

Nos anos de 2012, 2013 e 2014, no sistema ILP (calculado para $11 \mathrm{ha}$ ), a produção total de milho (grãos) obtida foi de 68 200, 81400 e 82775 kg/ano, respectivamente. A produção de silagem de milho total foi de 336 105,

Tabela II. Produtividade e produção total das culturas de milho e feijão caupi no sistema integração lavoura-pecuária (ILP) ajustados para 11 ha durante o período de 2012 a 2015 (Crop production in integrated systems adjusted to 11 ha for the period from 2012 to 2015).

\begin{tabular}{lcc}
\hline Milho (grãos) & Produtividade (kg/ha) & Produção $(\mathrm{kg})$ \\
\hline 2012 & 6200 & 68200 \\
2013 & 7400 & 81400 \\
2014 & 7525 & 82775 \\
$2015^{*}$ & 6531 & 71841 \\
\hline Silagem Milho (MO) & & 336105 \\
\hline 2012 & 30555 & 338965 \\
2013 & 30815 & 341825 \\
2014 & 31075 & 338965 \\
$2015^{*}$ & 30815 & \\
\hline Caupi (grãos) & 1163 & 12793 \\
\hline 2012 & 1355 & 14905 \\
2013 & 734 & 824 \\
2014 & 1084 & 119 \\
$2015^{*}$ & & \\
\hline
\end{tabular}

*Estimativa usando a média das produtividades anteriores. 


\begin{tabular}{lcc}
\hline \multicolumn{1}{l}{ Tabela III. Produtividade e produção total das cul- } \\
turas de milho e feijão caupi no sistema integração \\
lavoura pecuária floresta (ILPF) ajustados para 10 \\
ha durante o período de 2012 a 2015 (Crop production \\
in forest integrated systems adjusted to 11 ha in the period from \\
2012 to 2015). & & \\
\hline Milho (grãos) & Produtividade (kg/ha) & Produção (kg) \\
\hline 2012 & 6200 & 62000 \\
2013 & 7400 & 74000 \\
2014 & 7135 & 71350 \\
$2015^{*}$ & 6433 & 64330 \\
\hline Silagem milho (MO) & & 305550 \\
\hline 2012 & 30555 & 270270 \\
2013 & 27027 & 235000 \\
2014 & 23500 & 270270 \\
2015 & 27027 & 8370 \\
\hline Caupi (grãos) & & 10050 \\
\hline 2012 & 837 & 9150 \\
2013 & 1005 & 9190 \\
2014 & 915 & \\
2015 & 919 & \\
\hline
\end{tabular}

*Estimativa usando a média das produtividades anteriores.

228965 e 341825 kg/ano. A produção de feijão caupi foi de 12 793, 14905 e $11924 \mathrm{~kg} /$ ano, respectivamente (tabela II). Para o sistema ILPF (calculado para 10 ha, 11 ha descontando-se a área destinada às árvores), durante os anos de 2012, 2013 e 2014 foi obtida uma produção total de 62000,74000 e $71350 \mathrm{~kg}$, respectivamente, quando cultivado o milho para a produção de grãos. Quando cultivado milho para a produção de silagem, obteve-se uma produção anual de 305 550, 270270 e $235000 \mathrm{~kg}$ de $\mathrm{MV} / \mathrm{ha}$. Produções anuais de 8 370, 10050 e $9150 \mathrm{~kg} /$ ha foram obtidas com o cultivo do feijão caupi, nos três anos de avaliação (tabela III).

No início do período de coleta dos dados de desempenho, os animais apresentaram $275 \mathrm{~kg}$ de peso corporal médio. $\mathrm{O}$ ganho de peso corporal médio das novilhas avaliado no sistema ILP foi de $500 \mathrm{~g} /$ animal.dia e a taxa de lotação obtida foi de 5,74 U.A./ha. Já, no sistema ILPF, o ganho de peso corporal médio foi de $520 \mathrm{~g} /$ animal.dia e a taxa de lotação obtida foi de 5,36 U.A./ ha. Valores semelhantes foram obtidos por Nantes et al. (2013) em capim-piatã manejado em monocultivo.
Os sistemas integrados apresentaram VPLs positivos a uma taxa de desconto de $10 \%$ ao ano, sendo viáveis economicamente (tabela IV). Por apresentarem VPL positivo, os sistemas integrados podem ser implantados, pois nesta condição seria possível cobrir os seus custos de implantação e manutenção (Dantas, 1996), ou seja, as receitas advindas com a exploração da atividade seriam suficientes para cobrir as despesas necessárias para produzir e ainda, seria possível recuperar o capital financeiro investido nos sistemas de produção integrada.

A TIR obtida foi de 11,37 e 10,73\%, respectivamente, para o ILP e ILPF. Ao adotar os rendimentos obtidos com a aplicação financeira na caderneta de poupança como a taxa mínima de atratividade para o investidor, pode-se considerar que os sistemas de produção integrada são atrativos para investimento. No mesmo período de avaliação experimental, a rentabilidade média obtida com a caderneta de poupança oscilou entre $6,37 \%$ e 7,45\% a.a. (Portal Brasil, 2015). Segundo Contador (1988), o sistema integrado que apresentar a maior TIR será indicado para investimento, do ponto de vista econômico. Para o horizonte de estudo (14 anos), a receita obtida com a atividade foi suficiente para cobrir os custos de produção envolvidos na implantação e manutenção dos sistemas integrados, remunerando o capital investido equivalente a taxa de desconto aplicada. A adoção destes sistemas pode ser considerada vantajosa para aplicação do capital financeiro no longo prazo, uma vez que a taxa de desconto aplicada foi superior à taxa mínima de atratividade (rendimentos pagos pela caderneta de poupança), considerada neste trabalho. A adoção da caderneta de poupança como referência ao investimento, segundo Peres (2006) é indicada por se tratar de uma aplicação financeira disponível no mercado, levando em consideração a facilidade de adesão por parte dos produtores e ou para outros investidores, além de ser uma aplicação que apresenta baixo risco econômico-financeiro de investimento. Estudo realizado por Silva et al. (2012) em sistemas integrados de produção na região de Castro-PR demonstrou ser viável financeiramente a adoção dessa tecnologia, onde a integração lavoura-pecuária apresentou rentabilidade positiva, sendo mais atrativa para investimento, quando comparada ao sistema agrícola convencional explorado na região. Os diferentes sistemas de pastagens diversificadas explorados na região apresentaram margem líquida positiva, ao passo que o sistema agrícola convencional apresentou margem líquida negativa, o que significa que na integração lavoura-pecuária a receita bruta obtida foi suficiente para cobrir o custo operacional total do sistema, resultando em rentabilidade positiva para atividade. Os sistemas apresentaram os

Tabela IV. Valor presente líquido - VPL, em R\$, submetido a diferentes taxas de desconto e taxa interna de retorno - TIR, em \%, obtida para os sistemas integrados - integração lavoura pecuária (ILP) e integração lavoura pecuária floresta (ILPF) (Net present value - NPV, in R\$, under different discount rates and internal rate of return - IRR, in \%, obtained for each integrated systems - CLI and CLFI).

\begin{tabular}{|c|c|c|c|c|c|}
\hline \multirow{2}{*}{ Sistema de produção } & \multicolumn{4}{|c|}{ VPL } & \multirow{2}{*}{ TIR } \\
\hline & $6 \%$ & $8 \%$ & $10 \%$ & $12 \%$ & \\
\hline Integração lavoura-pecuária & 756070,48 & 414945,90 & 148784,72 & $-60326,52$ & 11,37 \\
\hline Integração lavoura-pecuária-floresta & 625442,98 & 316544,70 & 74639,55 & - 116143,95 & 10,73 \\
\hline
\end{tabular}


melhores resultados econômicos, sendo considerados a alternativa mais rentável aos produtores.

O tempo de recuperação do capital investido (payback descontado) foi de oito anos e oito meses para o ILP e de oito anos e três meses para o ILPF. A implicação disto é que, a partir desse período, o excedente financeiro obtido é considerado como lucro e deverá ser reinvestido no sistema de produção para ampliação ou melhorias. A adoção de qual sistema de produção integrada deverá ser feita pelo investidor deverá ser definida em função da capacidade técnica e gerencial do proprietário, bem como da capacidade financeira em investir. O produtor deve avaliar as recomendações técnicas para implantação e exploração do sistema de produção integrada escolhido, bem como a sua adaptação ao local em que a atividade será explorada, para que não ocorra perdas produtivas ou insucesso na atividade de integração. Aspectos mercadológicos para comercialização dos produtos advindos da atividade também deve ser levado em consideração.

Com a realização da análise de sensibilidade, observou-se a influência dos itens componentes de cada sistema integrado frente às oscilações de preços ocorridas no mercado. Foi observado o impacto negativo causado no fluxo de caixa, por cada item de produção, sempre no sentido desfavorável ao produtor. A partir da análise foi possível determinar em que medida um erro ou modificação de uma das variáveis, incidiu nos resultados do projeto (Buarque, 1991). Os itens componentes do sistema avaliado foram submetidos a uma desvalorização

Tabela V. Mudança do valor presente líquido (VPL), em R\$, decorrente de uma variação de $10 \%$ dos preços dos itens que compõem os sistemas de produção integrada, para uma taxa de desconto de $6 \%$ ao ano (Change de NPV, in R\$, for a variation in the unfavourable direction, $10 \%$ in price components of integrated production systems at a $6 \%$ discount rate per year).

\begin{tabular}{|c|c|c|}
\hline Sistema de produção & Categoria & $\mathrm{R} \$$ \\
\hline \multirow{15}{*}{ Integração lavoura-pecuária } & Venda de novilha com prenhez confirmada & - R\$ 390369,68 \\
\hline & Compra de bezerra desmamada & - R\$ 148699,88 \\
\hline & Compra de terra & - $\mathrm{R} \$ 62246,70$ \\
\hline & $\begin{array}{l}\text { Contratação de mão de obra permanente (cam- } \\
\text { peiro) }\end{array}$ & - R\$ 17019,64 \\
\hline & Venda de milho em grão & - $R \$ 16313,81$ \\
\hline & Compra de adubo para plantio $(04-30-16)$ & - $\mathrm{R} \$ 11432,24$ \\
\hline & Contratação de mão de obra administrativa & - $\mathrm{R} \$ 11019,62$ \\
\hline & Compra de sal mineral & - R\$ 9635,11 \\
\hline & $\begin{array}{l}\text { Contratação de serviços terceirizados (hora- } \\
\text { máquina) }\end{array}$ & - R\$ 9549,87 \\
\hline & Pagamento de encargos trabalhistas e sociais & - R\$ 9001,47 \\
\hline & Compra de adubo para cobertura $(20-00-20)$ & - $\mathrm{R} \$ 8816,59$ \\
\hline & Venda de feijão caupi & - $\mathrm{R} \$ 8119,56$ \\
\hline & Compra de veículo quadriciclo & - $\mathrm{R} \$ 7815,13$ \\
\hline & Compra de semente de milho & - R\$ 7348,38 \\
\hline & Venda de novilha de descarte & - R\$ 6299,39 \\
\hline \multirow{15}{*}{ Integração lavoura-pecuária-floresta } & Venda de novilha com prenhez confirmada & - R\$ 339528,98 \\
\hline & Compra de bezerra desmamada & - $\mathrm{R} \$ 115411,64$ \\
\hline & Compra de terra & - $\mathrm{R} \$ 62246,70$ \\
\hline & $\begin{array}{l}\text { Contratação de mão de obra permanente (cam- } \\
\text { peiro) }\end{array}$ & - $\mathrm{R} \$ 17019,64$ \\
\hline & Venda de milho em grão & - $\mathrm{R} \$ 14581,84$ \\
\hline & Contratação de mão de obra administrativa & - $\mathrm{R} \$ 11019,62$ \\
\hline & $\begin{array}{l}\text { Contratação de serviços terceirizados (hora- } \\
\text { máquina) }\end{array}$ & - R\$ 9540,55 \\
\hline & Compra de adubo para plantio $(04-30-16)$ & - R\$ 9114,90 \\
\hline & Pagamento de encargos trabalhistas e sociais & - R\$ 9001,47 \\
\hline & Compra de sal mineral & - $\mathrm{R} \$ 8635,93$ \\
\hline & Compra de adubo para cobertura $(20-00-20)$ & - R\$ 8199,54 \\
\hline & Venda de eucalipto para lenha & - R\$ 8097,26 \\
\hline & Compra de veículo quadriciclo & - $\mathrm{R} \$ 7815,13$ \\
\hline & Venda de feijão caupi & - $\mathrm{R} \$ 6234,32$ \\
\hline & Compra de semente de milho & - R\$ 6080,11 \\
\hline
\end{tabular}


de dez pontos percentuais nos preços, para as receitas e adicionado em dez pontos percentuais nos preços dos itens de despesas. Esta ferramenta permitiu observar o impacto negativo exercido sobre os resultados obtidos para o VPL, quando este foi submetido à taxa de desconto de $6 \%$ ao ano.

Neste cenário, para os sistemas integrados analisados, o indicador econômico de rentabilidade (VPL) foi mais sensível à variação de preços considerados na venda das novilhas leiteiras com prenhez confirmada de quatro meses (tabela V). Este item foi o que mais afetou o fluxo de caixa nos sistemas, durante o horizonte analisado, sendo seguido, pelo preço de compra da bezerra desmamada. $\mathrm{O}$ comportamento destes itens refletiu o quanto a pecuária leiteira da região é dependente da oferta de animais de qualidade, que geralmente são oriundos de outros estados brasileiros. Os animais geralmente comercializados na região apresentam alta valorização e nem sempre qualidade genética compatíveis com o preço de aquisição. Conhecer os itens de maior impacto e que influenciam os resultados da atividade permite ao investidor realizar um planejamento, quando o assunto é inerente ao comportamento de mercado e a comercialização dos produtos. Na gestão da atividade, o produtor deve sempre buscar o melhor momento para vender suas novilhas, buscando sempre vendê-las por preços superiores aqueles preços médios praticados na região e ainda, ao comprar as bezerras para reposição de animais no sistema, aliar as características zootécnicas, considerando o potencial genético dos animais, aos preços de compra. Comprar animais com preços atrativos e vendê-los com melhores preços permitem ao produtor obter melhor rentabilidade financeira em sua atividade. Esses resultados corroboram com aqueles encontrados por Peres et al. (2004) e Peres et al. (2015) que observaram o preço de venda das novilhas e o preço de compra das bezerras serem os itens de produção de maior influência nos resultados de sistemas de produção destinados a criação de novilhas leiteiras. O terceiro item mais sensível foi o preço de compra da terra para implantação e exploração da atividade. Este item pode ser um indicativo que devido aos altos preços da terra, praticados na região, devido à pressão da lavoura sobre as áreas de pecuária, um possível investidor deveria analisar outras possibilidades de aquisição de terras em regiões onde o preço do hectare for mais acessível. Explorar a terra em seu potencial máximo aliando agricultura e pecuária pode ser atrativo e melhorar a rentabilidade da atividade (Embrapa, 2011). O uso da terra deve ser realizado de forma consciente e sustentável, não levando a degradação e início de erosão, pois certamente promoverão a desvalorização do bem, res- saltando que a imobilização de capital financeiro neste item de produção é alta. Devido a isso, o correto manejo dos solos, da pastagem e do sistema de produção como um todo, deve ser a premissa principal de um produtor, quando este deseja recuperar o investimento realizado. Deve-se considerar que, nestas áreas tradicionais de pecuária, a logística para entrada de insumos e saída de grãos pode onerar a atividade. Por outro lado, os preços praticados, principalmente, do milho e feijão-caupi poderiam ser mais elevados nesta região, uma vez que estes aparecem entre os quinze itens que mais afetaram o VPL para a taxa de desconto de $6 \%$ ao ano. Vale ressaltar ainda que, os itens relacionados à mão de obra afetaram o VPL pelo fato desta competir diretamente com mão de obra demandada na área urbana (da construção civil e de prestação de serviços), que remunerando melhor, alavancaram os preços praticados na zona rural, assim, como sua disponibilidade. Os preços dos insumos, como adubo e sal mineral, mostraram-se mais elevados devido a escala de aquisição ser pequena quando comparada às grandes compras feitas pelas propriedades da região. Visando reduzir os preços de compras destes insumos, uma alternativa pode ser a compra em maior escala, ou se possível, o produtor se tornar um cooperativado para que tivesse direito aos benefícios na compra, com a redução de impostos, quando a compra fosse realizada por uma cooperativa agrícola. $\mathrm{O}$ preço da madeira de eucalipto para lenha apareceu como item sensível para o sistema ILPF, ressaltando a importância do componente florestal no sistema. Vale ressaltar que o indicativo de conduzir a madeira para serraria agregaria mais valor neste componente no sistema ILPF.

Contudo, os sistemas não podem ser comparados economicamente, pois são pacotes tecnológicos diferentes, apresentando características distintas e peculiaridades individuais. Cada produtor ou investidor deverá optar pelo sistema que melhor se adapte à sua realidade, ou à demanda da região. Como exemplo, poderia ser citada uma situação em que um produtor optasse pelo sistema ILPF e se a área estivesse muito distante da indústria ou de centros consumidores desta matéria-prima, o seu principal fator limitante seria a comercialização da madeira, tornando o negócio difícil ou mesmo inviável. Ao optar pelo sistema ILP, o limitante poderia ser o conforto térmico dos animais que afetaria o resultado final, não somente econômico, mas produtivo e reprodutivo, além da conscientização em relação ao bem-estar animal perante a sociedade moderna. Caberia ao interessado, avaliar alguns itens que compõem cada sistema e definir qual sistema seria mais adequado ao seu perfil do investidor, seja ele do ponto de vista tecnológico ou financeiro.

Tabela VI. Resultado da análise probabilística do risco: probabilidade, em \%, dos sistemas integração lavoura pecuária (ILP) e integração lavoura pecuária floresta (ILPF) apresentarem valor presente líquido (VPL) negativo, quando submetido a diferentes taxas anuais de desconto de $6 \%, 8 \%, 10 \%$ e $12 \%$. (Result of risk probabilistic assessment: probability, in \%, of the CLI and CLFI systems showing the negative net present value (NPV), when subjected to different annual discount rates at $6 \%, 8 \%, 10 \%$ and $12 \%)$.

\begin{tabular}{lccc} 
& & \multicolumn{2}{c}{ Taxa de desconto } \\
\cline { 2 - 4 } Sistema de produção & $6 \%$ & $8 \%$ & $10 \%$ \\
\hline Integração lavoura-pecuária & $0,25 \%$ & $1,72 \%$ & $7,97 \%$ \\
Integração lavoura-pecuária-floresta & $0,76 \%$ & $24,53 \%$ & $23,18 \%$ \\
\hline
\end{tabular}




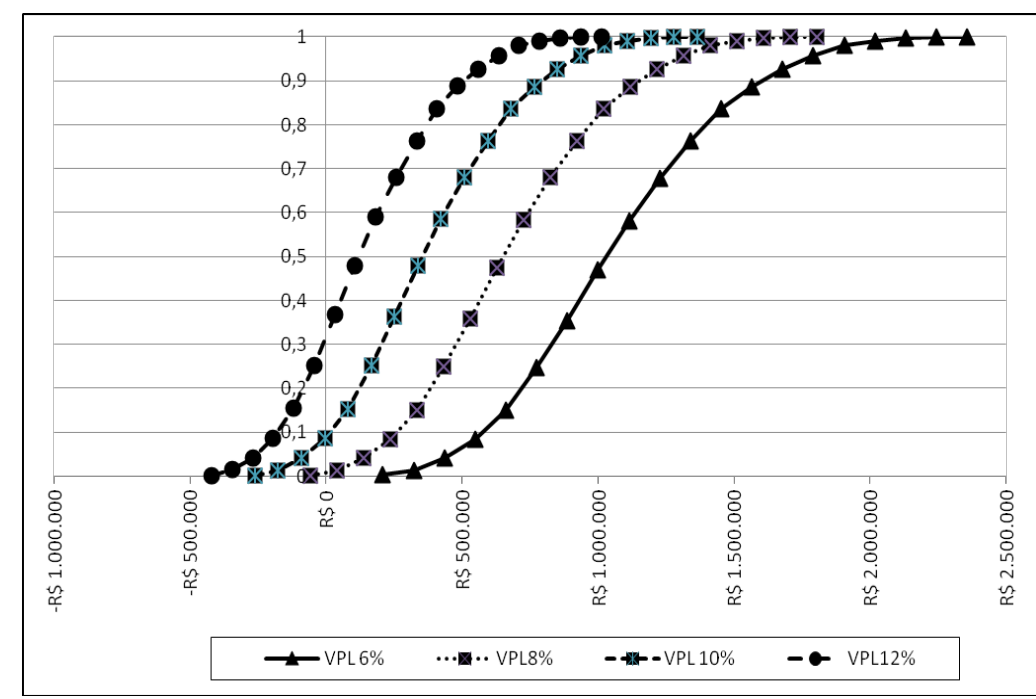

Figura 2. Frequência acumulada dos valores presentes líquidos (VPL) simulados a diferentes taxas de desconto para o sistema de integração lavoura-pecuária (Cumulative frequency of the net present values simulating the different discount rates for the crop-livestock integration system).

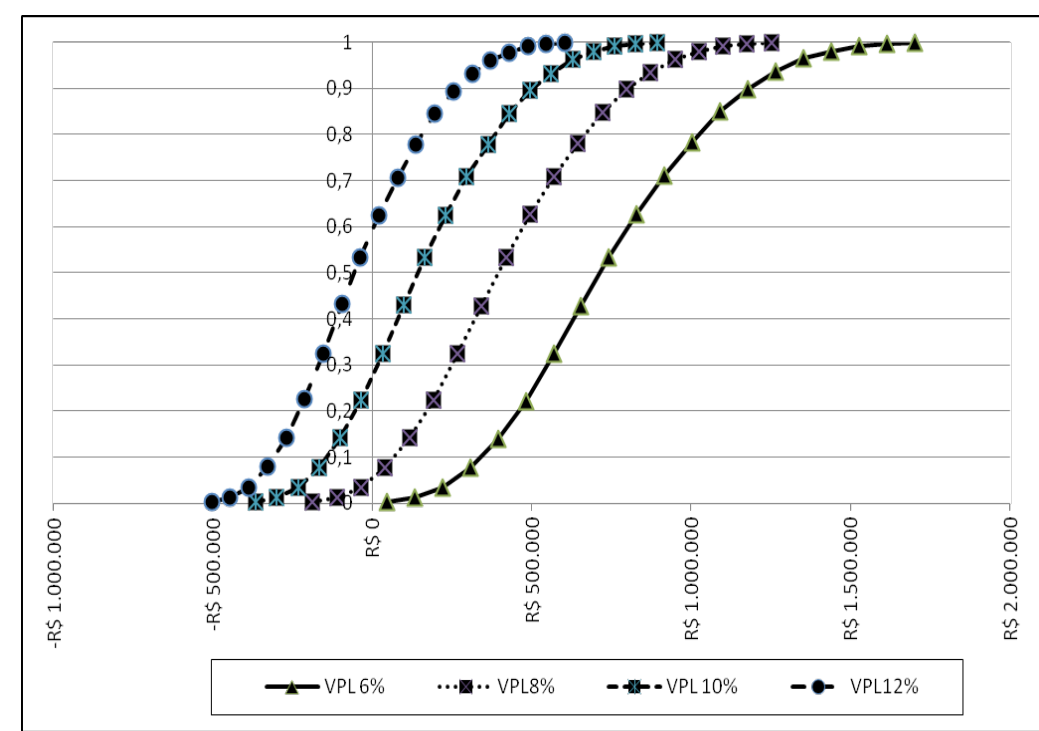

Figura 3. Frequência acumulada dos valores presentes líquidos (VPL) simulados a diferentes taxas de desconto para o sistema de integração lavoura-pecuária-floresta (Cumulative frequency of the net present values simulating the different discount rates for the crop-livestock-forest integration system).

De acordo com a análise probabilística de risco, conforme o método de Monte Carlo (Blank e Tarquin, 2008), os sistemas não apresentaram risco econômico de se tornarem inviáveis financeiramente a uma taxa de desconto de $12 \%$ para o ILP e a $10 \%$ para o ILPF (tabela VI). Por se tratarem de sistemas que exploram a criação de animais exclusivamente em pastagens cultivadas, implantadas dentro das recomendações técnicas para uma boa produção forrageira e recuperada periodicamente com uso da lavoura, o risco observado em $24,53 \%$ e 23,18\% para o ILP e ILPF, respectivamente, pode ser considerado baixo. Com a diversificação de atividades nos sistemas de produção com exploração agrícola, pecuária e de silvicultura em pastagens cultivadas, observaram-se melhores condições de criação e sustentabilidade ambiental. Esses resultados assemelharam-se aos encontrados por Peres et al. (2015), que encontraram baixo risco financeiro, a uma taxa de desconto de $10 \%$ a.a., em sistemas de produção para novilhas leiteiras manejadas em pastagem de capim-Xaraés e suplementadas com misturas minerais, sendo observado um risco de $21,33 \%$ e de $14,63 \%$, para os sistemas que adotaram a mistura mineral comercial e a mistura mineral seletiva, respectivamente.

$\mathrm{O}$ risco da atividade de se tornar inviável economicamente nos dois sistemas aumenta, caso seja aplicada uma taxa de desconto maior sobre o capital fixo e circulante do investimento. A variação do preço de compra e venda dos animais não se apresentou como fator de risco aos sistemas, uma vez que o mercado de animais jovens não é muito afetado pelo preço do leite ou estacionalidade, ao contrário de novilhas que, geralmente, são bem valorizadas por ser uma opção mais segura de investimento. Além disso, sistemas que proporcionem maior segurança alimentar ao rebanho e que reduzam a idade ao primeiro parto são indicados como economicamente mais viáveis na criação de novilhas (Tozer e Heinrichs, 2001). Santos e Lopes (2014) avaliaram o centro de custo de novilhas leiteiras da raça Holandesa e mestiças. Os autores consideraram 90 dias de aleitamento e $360 \mathrm{~kg}$ para realização da inseminação artificial. O lote de animais da raça Holandesa foi inseminado entre 14 e 16 meses, enquanto que o lote das novilhas mestiças foi inseminado entre 19 e 21 meses de idade. Sendo assim, a idade ao primeiro parto ocorreu entre 23 e 25 meses. Neste, os autores observaram que os custos totais de produção de uma fêmea bovina leiteira da raça Holandesa e mestiça foram de R 33240,28 e R $\$ 2$ 857,15, respectivamente. No entanto, a idade ao primeiro parto nas fêmeas puras foi antecipada em 89 dias. Os itens com maior representatividade no custo operacional efetivo foram à alimentação, mão de obra e despesas diversas, em ambos os sistemas de produção, demonstrando que a precocidade na novilha é benéfica ao custo final de produção, pois promove a redução do custo operacional efetivo.
As figuras 2 e 3 ilustraram a distribuição das frequências acumuladas dos 50000 VPLs que foram simulados a partir dos preços mínimo, médio e máximo deflacionados, considerando os quinze itens identificados na análise de sensibilidade, que exerceram maior impacto negativo sobre os respectivos VPLs nos dois sistemas de produção integrada avaliados. Ressalta-se que na realização da análise probabilística do risco, assim como apresentado por Peres et al. (2008), não se consideraram os riscos econômicos provocados por fenômenos naturais, nem mesmo possíveis mudanças climáticas que pudessem influenciar na produção agrícola, pecuária ou de madeira, bem como nos resultados econômicos dos sistemas integrados de produção. Neste trabalho, foi considerado apenas o risco financeiro do negócio que levou em conta os preços praticados na região de todos os itens componentes de cada sistema integrado de produção. Como as ava- 
liações realizadas neste trabalho foram projetadas para um horizonte de 14 anos, a remuneração do capital investido, bem como, os índices financeiros gerados, deve ser visualizada por um período de longo prazo.

\section{CONCLUSÕES}

Os sistemas integrados de produção de novilhas leiteiras na região Norte do Estado de Mato Grosso com ou sem associação com árvores são viáveis economicamente e apresentam baixo risco financeiro para investimento. O capital financeiro investido nos sistemas integrados é remunerado a taxa superior aos rendimentos obtidos com a caderneta de poupança, no mesmo período. Por apresentarem um período de longo prazo para recuperação do capital investido, o investidor deve estar atento aos preços de comercialização dos animais, na venda das novilhas leiteiras com prenhez confirmada e na compra das bezerras desmamadas, pois no fluxo de caixa, estes são os itens identificados que causam maior impacto negativo nos resultados dos sistemas integrados de produção.

\section{BIBLIOGRAFIA}

Atkinson, A.A.; Kaplan, R.S.; Matsumura, E.M. e Young, S.M. 2015. Contabilidade gerencial: informação para tomada de decisão e execução da estratégia. $4^{a}$ ed. Editora Atlas. São Paulo, SP. 448 pp.

Blank, L. e Tarquin, A. 2008. Engenharia econômica. $6^{a}$ ed. McGrawHill. São Paulo, SP. 756 pp.

Buarque, C. 1991. Avaliação econômica de projetos. $8^{a}$ ed. Editora Campus. Rio de Janeiro, RJ. 266 pp.

Carnevalli, R.A.; Silva, S.C.; Bueno, A.A.O.; Uebele, M.C.; Bueno, F.O.; Hodgson, J.; Silva, G.N. e Morais, J.P.G. 2006. Herbage production and grazing losses in Panicum maximum cv. Mombaça under four grazing managements. Trop Grasslands, 40: 165-176.

Contador, C.R. 1988. Avaliação social de projetos. $2^{a}$ ed. Editora Atlas. São Paulo, SP. 316 pp.

Dantas, A. 1996. Análise de investimentos e projetos aplicada à pequena empresa. $8^{a}$ ed. Editora da Universidade de Brasília. Brasília, DF. 162 pp.

Empresa Brasileira de Pesquisa Agropecuária - EMBRAPA. 2011. Marco referencial integração lavoura-pecuária-floresta. In: Balbino, L.C.; Barcellos, A.O. e Stone, L.F. (Eds.). $1^{a}$ ed. Editora Embrapa Brasília, DF. 130 pp.

Federação da Agricultura e Pecuária do Estado de Mato Grosso FAMATO, Serviço Nacional de Aprendizagem Rural no Estado de Mato Grosso - SENAR-MT, Serviço Nacional de Aprendizagem em Cooperativismo no Estado de Mato Grosso - SESCOOP-MT. 2012. Diagnóstico da cadeia produtiva do leite no Estado de Mato Grosso: relatório de pesquisa. In: Gabriel Rodrigues Gomes (Ed.). 2.ed. Famato. Cuiabá. 109 pp.

Fundação Getúlio Vargas - FGV. 2015. Índice geral de preços - disponibilidade interna. Revisão atualizada diariamente. http://www. antigofgrdados.fgv.br (08/05/2015).

Ghosh, P.K. 2004. Growth, yield, competition and economics of groundnut/cereal fodder intercropping systems in the semi-arid tropics of India. Field Crop Res, 88: 227-237.

Hertz, D. 1964. Risk analysis in capital investment. Harvard Bus Rev, 42: $95-106$
Hoffman, P.C. e Funk, D.A. 1992. Applied dynamics of dairy replacement growth and management. J Dairy Sci, 75: 2504-2516.

Jianbo, L. 2006. Energy balance and economic benefits of two agroforestry systems in northern and southern China. Agr Ecosyst Environ, 116: 255-262.

Martin, R.C.; Voldeng, H.D. e Smith. D.L. 1990. Intercropping corn and soybean for silage in a cool-temperature region: yield, protein and economic effects. Field Crop Res, 23: 295-310.

Nantes, N.N.; Euclides, V.P.B.; Montagner. D.B.; Lempp, L.; Barbosa, R.A. e Gois, P.O. 2013. Desempenho animal e características de pastos de capimpiatã submetidos a diferentes intensidades de pastejo. Pesqui Agropecu Bras, 48: 114-121.

Noronha, J.F. 1987. Projetos agropecuários: administração financeira, orçamento e viabilidade econômica. $2^{a}$ ed. Editora Atlas. São Paulo, SP. 269 pp.

Oda, A.L.; Graça, C.T. e Leme, M.F.P. 2007. Análise de riscos de projetos agropecuários: um exemplo de como fundamentar a escolha entre projetos alternativos e excludentes. ftp://ftp.est.ufmg.br/pub/lupercio/ management/sem_0716.pdf (10/09/2015).

Ostrowski, B. e Deblitz, C. 2001. La competitividad em producción lechera de los países de Chile, Argentina, Uruguay y Brasil. Livestock policy discussion. Food and Agriculture Organization. Paper n.4. September. 130 pp.

Peres, A.A.C. 2006. Viabilidade técnica e econômica de sistemas de produção a pasto para vacas em lactação sob manejo rotacionado. Tese de Doutorado. Universidade Estadual do Norte Fluminense. 181 pp.

Peres, A.A.C.; Santos, A.A.; Carvalho, C.A.B. e Brandalise, N. 2015. Análise financeira de sistemas de produção para novilhas em pastagem de Brachiaria brizantha 'Xaraes' suplementadas com mistura mineral. Arch Zootec, 64: 123-130.

Peres, A.A.C.; Souza, P.M.; Maldonado, H.; Coelho da Silva, J.F.; Soares, C.S.; Barros, S.C.W. e Haddade, I.R. 2004. Análise econômica de sistemas de produção a pasto para bovinos no município de Campos dos Goytacazes-RJ. Rev Bras Zootecn, 33: 1557-1563.

Peres, A.A.C.; Souza, P.M.; Vasquez, H.M.; Coelho da Silva, J.F.; Carvalho, C.A.B.; Carvalho, J.B.P. e Morenz, M.J.F. 2008. Análise financeira sob condições de risco de sistemas de produção de leite na região do Vale do Paraíba, SP. B. Indústr Anim, 65: 35-42.

Portal Brasil. 2015. Caderneta de poupança: índices mensais. http:// www.portalbrasil.net/poupanca_mensal.htm (02/06/2015).

Santos, G.; Lopes, M.A. 2014. Custos de produção de fêmeas bovinas leiteiras do nascimento ao primeiro parto Cienc Anim Bras, 15: 11-19.

Silva, H.A.; Moraes, A.; Carvalho, P.C.F.; Fonseca, A.F.; Guimarães, V.A.; Monteiro, A.L.G. e Lang, C.R. 2012. Viabilidade econômica da produção de novilhas leiteiras a pasto em sistema integração lavoura-pecuária. Pesqui Agropecu Bras, 47: 745-753.

Tozer, P.R. e Heinrichs, A.J. 2001. What affects the costs of raising replacement dairy heifers: a multiple-component analysis. J Dairy Sci, 84: 1836-1844.

Urtado, E.S; Santos, V.S; Quintairos, P.C.R. e Oliveira, E.A.A.Q. 2009. Aplicação do método do valor presente líquido (VPL) na análise da viabilidade econômica de projetos na indústria metal mecânica: um estudo de caso. XIII Encontro Latino Americano de Iniciação Científica e IX Encontro Latino Americano de Pós-Graduação. Universidade do Vale do Paraíba. UNIVAP. 